J. clin. Path., 1976, 29, 1074-1076

\title{
Renal biopsy in the milk-alkali syndrome
}

\author{
B. J. R. JUNOR AND G. R. D. CATTO \\ From the Department of Medicine, University of Aberdeen
}

SYNOPSIS In milk-alkali syndrome the degree of renal impairment varies greatly. Few reports have been published describing structural changes on renal biopsy. In three illustrative cases, impairment of renal function was related to morphological changes shown on percutaneous biopsy. Milk-alkali syndrome should be considered as a cause of renal dysfunction in patients with a long history of dyspepsia.

Although nephrocalcinosis has been recognized for many years as a complication of the milk-alkali syndrome, almost all the material available for histological examination has been obtained at necropsy (Burnett et al, 1949; Wermer et al, 1953; DuFault and Tobias, 1954; Kyle, 1954; Holten and Lundbaek, 1955). When documented in detail the findings were of marked tubular atrophy, an increase in interstitial connective tissue, diffuse lymphocytic infiltration, extensive calcification of tubular cells, and deposition of calcium masses in the tubular lumina. Glomeruli showed partial to complete hyalinization and prominent thickening of Bowman's capsule.

There have been very few reports of the findings on renal biopsy. Randall et al (1961) described two cases of the milk-alkali syndrome in which there was evidence on renal biopsy of degeneration of tubular epithelium associated with collections of a granular material presumed to be calcium in and around the collecting tubules. In one patient with normal glomeruli there was a moderate increase in the interstitial fibrous tissue with a few scattered collections of lymphoid cells. The other biopsy showed hyalinization of several glomeruli, some thickening of the basement membrane, and loss of lobulation. Three months later both patients had a reduced glomerular filtration rate but a normal blood urea level. Scholz and Keating (1955) also described one patient with focal calcification in the renal tubules on biopsy secondary to prolonged milk and alkali ingestion who had a similar return to a normal blood urea level after an episode of uraemia.

The following case reports describe the histological appearances on biopsy of three patients with the

Received for publication 12 April 1976 milk-alkali syndrome (figure). The subsequent pro- $\mathrm{O}$ gress illustrates the varying severity of the syndrome.

\section{Case reports}

CASE 1

A 53-year-old man gave a 20-year history of recurrent dyspepsia relieved by a large intake of milk and of sodium bicarbonate which he took six times each day. In May 1975 he was admitted with a four-da⿳亠丷厂 history of epigastric pain and vomiting. Pyloric stenosis was confirmed on radiological examination which showed considerable resting gastric fluid with a giant penetrating ulcer on the greater curve but no evidence of nephrocalcinosis. As the blood urea remained persistently above $11 \mathrm{mmol} / \mathrm{l}$ a renal biopsy was carried out. After partial gastrectomy his dyspeptic symptoms subsided and the blood urea returned to normal.

\section{CASE 2}

A man aged 40 had persistent dyspeptic symptoms from the age of 15 and a haematemesis eight years later. He admitted to an intake of eight pints of milk and a large amount of sodium bicarbonate daily to alleviate his symptoms. After a second haematemesis he was found to have pyloric stenosis. On radiological examination the stomach was enlarged and $N$ filled with fluid, and there was gross deformity of the duodenal cap. On admission the blood urea was 39 $\mathrm{mmol} / \mathrm{l}$, falling to $12 \mathrm{mmol} / \mathrm{l}$ after rehydration and correction of electrolyte concentrations. There was, however, persistent proteinuria and after intravenous urography, which was normal, a renal biopsy was performed. After vagotomy and gastroenterostomy his symptoms were relieved. Nine months later the urine showed no abnormality but the blood urea remained raised at $11.6 \mathrm{mmol} / 1$. 


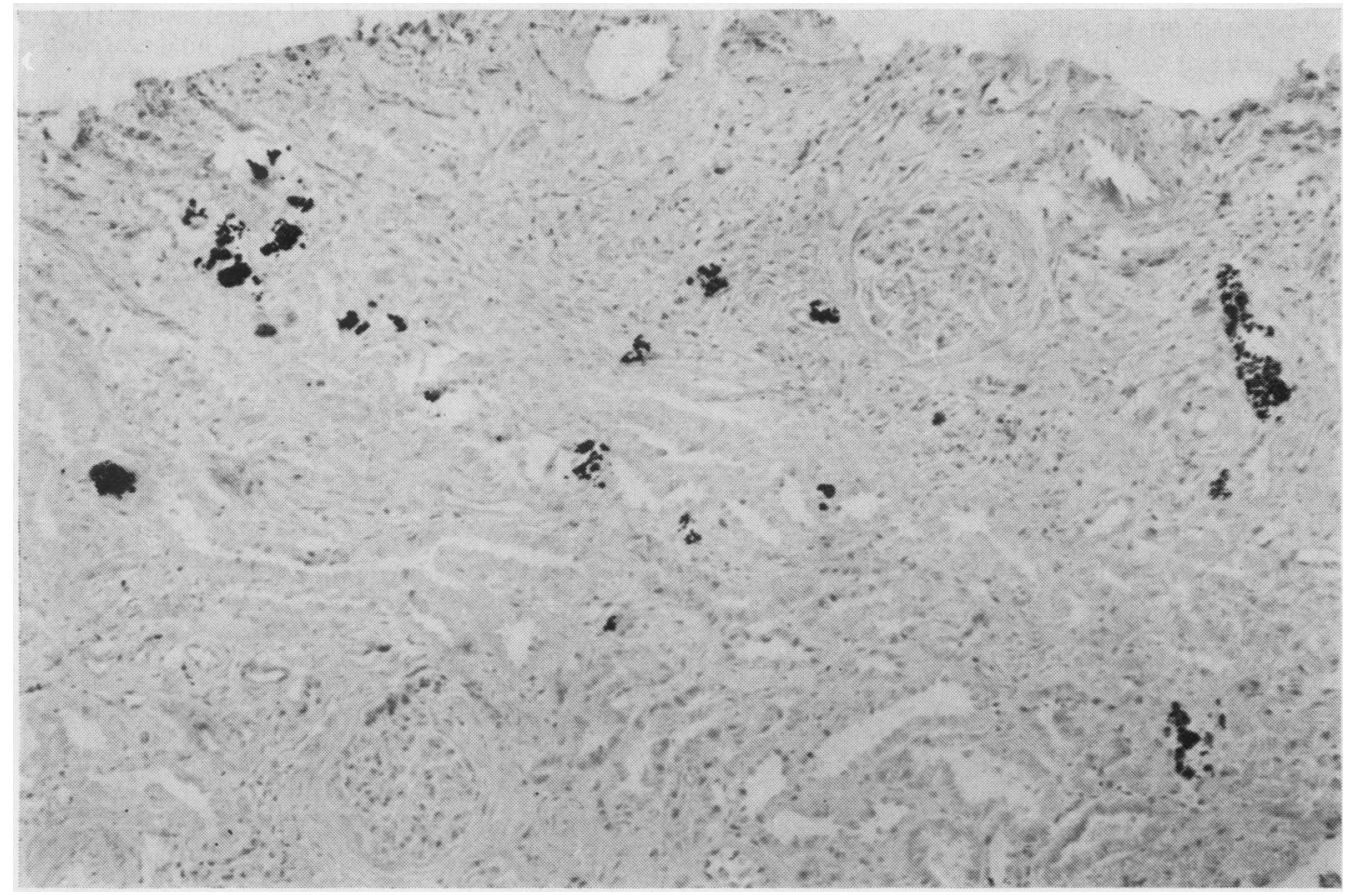

Figure Case 3. Renal biopsy. Von Kossa stain $\times 150$.

\section{CASE 3}

A man aged 47 had a long history of dyspeptic symptoms with perforations of duodenal ulcers at the age of 20 and again at 35 years. Two months after the second perforation he presented with nausea and vomiting and on radiological examination was shown to have a grossly dilated and hypertrophied stomach. Vagotomy and gastroenterostomy were performed but he continued to have symptoms which he relieved by large quantities of milk and sodium bicarbonate. In November 1974 he was admitted with nausea, vomiting and severe salt depletion. The blood urea was $39 \mathrm{mmol} / \mathrm{l}$. After fluid replacement the urea level fell to $12 \mathrm{mmol} / 1$ but proteinuria continued. After a normal intravenous urogram a renal biopsy was performed. Gastroscopy eight months later showed a stomal ulcer. The blood urea remained persistently above $10 \mathrm{mmol} / \mathrm{l}$.

\section{Histology}

All three biopsies showed focal calcium deposition within and adjacent to the renal tubules. Case 1 , in whom the blood urea level returned to normal, had the least evidence of calcium deposition, and the glomeruli were normal. Cases 2 and 3, who showed persistent renal impairment, had, in addition to the calcium deposition, interstitial fibrosis, areas of inflammatory reactive change, and periglomerular fibrosis.

Immunofluorescent studies in case 2 revealed a very faint deposition of IgG, complement, and fibrin, but in case 3 there was no evidence of immune globulin deposition.

\section{Discussion}

The ultimate prognosis depends on the severity of the histological changes on biopsy. Usually there is some improvement in renal function after correcting dehydration and electrolyte disturbance. In the first of the three illustrative cases reported here, who had least evidence of histological damage, normal renal function quickly returned. In the other two patients, however, functional impairment was still present up to nine months later, and there was histological evidence of permanent damage similar to the changes reported in earlier necropsy findings.

In the milk-alkali syndrome calcium deposition is not usually seen radiologically. This complication should be kept in mind when patients with a long history of self-medication for dyspeptic symptoms are found to have urinary abnormalities or impaired renal function.

We should like to thank Dr M. MacLeod and Dr N. 
Edward for permission to publish these cases and also the Department of Pathology, University of Aberdeen.

\section{References}

Burnett, C. H., Commons, R. R., Albright, F., and Howard, J. E. (1949) Hypercalcemia without hypercalcuria or hypophosphatemia, calcinosis and renal insufficiency. New Engl. J. Med., 240, 787-794.

DuFault, F. X., Jr., and Tobias, G. J. (1954). Potentially reversible renal failure following excessive calcium and alkali intake in peptic ulcer therapy. Amer. J. Med., 16, 231-236.
Holten, C. and Lundbaek, K. (1955). Renal insufficiency and severe calcinosis due to excessive alkali intake. Acta med: scand., 151, 177-183.

Kyle, L. H. (1954). Differentiation of hyperparathyroidism and the milk-alkali (Burnett) syndrome. New Engl. Jo Med., 251, 1035-1040.

Randall, R. E., Jr., Strauss, M. B., and McNeely, W. F. (1961). The milk-alkali syndrome. Arch. intern. Med., 107,, $\overrightarrow{\mathbb{D}}$ 163-181.

Scholz, D. A. and Keating, F. R., Jr. (1955). Milk-alkalip syndrome: review of 8 cases. Arch. intern. Med., 95, 460468.

Wermer, P., Kuschner, M., and Riley, E. A. (1953). Reversiblemetastatic calcification associated with excessive milk and alkali intake. Amer. J. Med., 14, 108-115. 